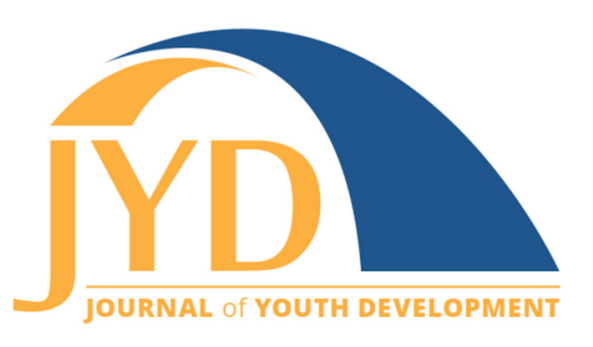

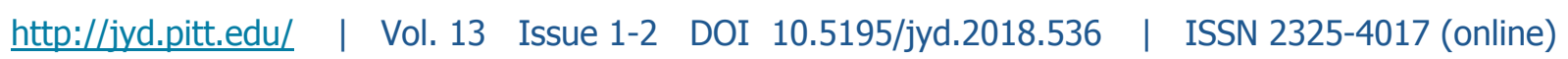

\title{
Summer Camp Youth Leadership Development: An Investigation of Adolescents' Perceptions of Best Practices
}

\author{
Katlyn Martin \\ McGill University; Indiana University \\ katlyn.martin@mail.mcgill.ca
}

\begin{abstract}
This qualitative study explored adolescent participants' perceptions of the Leaders-in-Training (LIT) program at Waycross Camp, a residential summer camp. The main data set was collected through interviews with former LIT program participants. A constant comparison data analysis of LIT program feedback revealed four emergent themes: (a) bridging the gap, (b) giving permission to be human, (c) rolling up your sleeves, and (d) serving the greater good. Each theme yielded an outcome, including (a) community, (b) openness, (c) empowerment, and (d) character, respectively. Concepts depicted in relevant literature were synthesized with these four themes and outcomes, yielding (a) social relationships; (b) identity and self-image; (c) agency and engagement; and (d) spirituality, ethicality, and morality, respectively. Together, these themes, outcomes, and concepts were integrated to produce a camp-based model of youth leadership development that reflected participant feedback on the LIT program's best practices. Implications for future practice are discussed.
\end{abstract}

Key words: youth development, leadership, camp

\section{Introduction}

Over the years, summer camp has become an American institution. It is a unique model of youth development with an elevated caliber of "duration, intensity, and breadth," placing it in a category unto its own (Garst, Browne, \& Bialeschki, 2011, p. 76-77). While enjoyable for many, for some camp is a transformative experience that has a lasting impact on personal interests, relationships, identity, and vocation (Garst, Franz, Peters, Smith, \& Baughman, 2012; Henderson, Bialeschki, \& James, 2007a; Thurber, Scanlin, Scheuler, \& Henderson, 2007).

(cc) $\mathrm{EY}_{\mathrm{EY}}$ New articles in this journal are licensed under a Creative Commons Attribution 4.0 License. This journal is published by the University Library System, University of Pittsburgh and is cosponsored by the University of Pittsburgh Press. The Journal of Youth Development is the official peer-reviewed publication of the National Association of Extension 4-H Agents and the National AfterSchool Association. 
Camp is both an educational organization and social movement (Thurber et al., 2007). Rooted in positive youth development (PYD), a prosocial, strengths-based perspective on adolescence, its objectives target adolescents' physical, emotional, educational, and civic growth (Catalano, Berglund, Ryan, Lonczak, \& Hawkins, 2004; Henderson, Whitaker, Bialeschki, Scanlin, \& Thurber, 2007c; Lerner, Almerigi, Theokas, \& Lerner, 2005). Seemingly paradoxical, camps can pose risks in a safe environment, cultivate mastery by introducing new skills, and create a sense of family while away from home. A critical catalyst of PYD, these characteristics distinguish camp from other educational and occupational settings (Eccles, Barber, Stone, \& Hunt, 2003; Henderson et al., 2007c; Ramsing \& Sibthorp, 2008; Thurber et al., 2007).

Camp leadership development programs are an anticipated rite of passage for many youth (Garst et al., 2011), often enriching campers' leadership skills and spurring significant change in their perceptions of leadership (Bialeschki, Henderson, \& James, 2007; Garst \& Johnson, 2005; Hastings, Barrett, Barbuto, \& Bell, 2011; Thomas, 1996). One study identified leadership as the domain with the most significant camper growth from pre- to post-camp (Henderson et al., 2007b). Garton, Miltenberger, and Pruett (2007) substantiated these findings, reporting that campers demonstrated significant, positive gains in seven areas related to leadership development. Interestingly, researchers identified additional gains linking campers' leadership development to camp experiences up to six months after the conclusion of camp (Thurber et al., 2007).

Since the about-face in the 1990s from a prevention science model in which youth are considered liabilities to PYD in which youth are considered assets, many youth leadership development programs' design, implementation, and evaluation have been reshaped and restructured using a strengths-based approach (Bialeschki et al., 2007; Henderson et al., 2007b; Roth \& Brooks-Gunn, 2003). Despite this paradigm shift, research suggests that contemporary youth leadership development programs often fall short. A 2007 benchmark study noted a discrepancy between intention and implementation, indicating that leadership development within a camp context is cited as one of several camp outcomes that demonstrates "the greatest potential for improvement" (Henderson et al., 2007a, p. 761). This gap between theory and practice is further examined in this study through the investigation of adolescents' perceptions of a youth leadership development program implemented in a summer camp setting. Based on grounded theory, this study's data analysis and research findings guided its conceptual framework and literature review, which concentrated on the intersection of PYD, youth leadership development, and camp research (Maxwell, 2013). 


\section{Method}

The purpose of this qualitative study was to explore adolescents' experiences at Waycross Camp's Leaders-in-Training (LIT) program. Specifically, this study sought to identify the strengths of the LIT program, a youth leadership development initiative implemented in a residential summer camp setting. By addressing LIT program participants directly, adolescent voices contributed to the bodies of research and literature that inform best practices.

\section{Program}

Waycross Camp is a residential summer camp situated in southern Indiana. On average, it runs between five to seven weeks from June to August each year. The camp caters to youth from grades 1-12 and sessions range from five to eight days in length. Sessions are classified as either adventure camp or specialty camp. In the former, youth in grades 1-8 are separated by age into adventure groups. Daily activities for adventure groups include swimming, biking, creek hiking, canoeing, rock climbing, zip lining, as well as arts and crafts, archery, mud pit, and low ropes course. During the week, each adventure group participates in an outdoor overnight, which entails hiking to a wooded location, preparing meals over an open fire, and sleeping on tarps under the stars (Waycross Camp and Conference Center, 2014).

The remaining camp sessions are classified as specialty camps. Examples of specialty camps include canoe camp, arts and crafts camp, wilderness camp, and the LIT program. The LIT program is geared towards adolescents who have completed at least grade 9 and at most grade 12 (Waycross Camp and Conference Center, 2014). Waycross Camp describes the LIT program as follows:

Learn to develop necessary skills for future leadership roles in a camp setting. Understand a counselor's role in taking initiative, in decision making, and in group leadership. Review and understand associated duties and responsibilities. You will also learn how to set and attain group goals, and identify personal strengths and talents that contribute to a well-balanced team of leaders. It's not all serious! LITs get to work hands-on with the younger campers and participate in classic camp activities including the mud pit and the rock wall. (Waycross Camp and Conference Center, 2014, para. 6) 


\section{Participants}

Twenty United States high school students ranging from 16 to 18 years old participated in the LIT program. A gender imbalance was apparent with 17 female and three male participants. Despite their varied family dynamics, ethnic backgrounds, and socioeconomic status, all LITs were involved in extracurricular activities, including athletics, music, and arts-based initiatives. Of these 20 adolescents, 10 took part in this study.

\section{Procedure}

Adhering to ethical guidelines, consent forms were obtained from all participants and from the parents of those under 18 . The primary data set was collected approximately 18 months after the LIT program's conclusion through structured, individual telephone interviews with LITs. The interview protocol began and ended with an opening and closing script that reiterated information included in the consent forms (e.g., purpose of study, confidentiality rights, Research Ethics Board contact information). Open-ended questions asked about participants' camp experiences, notions of leadership, and perceptions of LIT program application and value. Based on this format, interviews varied in length with none exceeding 45 minutes. Interview transcription included aspects of speech fluency, including sighs, pauses, and laughter. Aliases were assigned to participants based on the order in which the interviews were conducted (e.g., the first participant was recorded as Participant A). Reflexive memos were recorded after each interview.

\section{Analysis}

\section{Part 1: Themes}

After conducting and transcribing participants' interviews, data were analyzed thematically through constant comparison inquiry based on grounded theory (Butler-Kisber, 2010). Constant comparison is an inductive form of analysis that blends an exploratory research process, unguided by a priori hypotheses, with systematic, methodical approaches to data collection and analysis. Through this approach, responses to open-ended questions provided insight into the ways in which participants make meaning out of a given context (Butler-Kisber, 2010; Glaser \& Strauss, 2009). In grounded theory, theory is developed from data analysis and research findings, rather than the former framing the latter (Maxwell, 2013). The purpose of this approach was to explore the contextual elements that contributed to participants' LIT 


\section{Summer Camp Youth Leadership Development}

experiences without other researchers or theorists priming findings (Crooks, 2001; Maxwell, 2013).

During the constant comparison analytic process, key points were extracted from unitized data through coding (see Table 1). Coding is a technique in which patterns within data are indexed and a schematic, descriptive, or theoretical label is designated based on their properties, attributes, and dimensions (Gläser \& Laudel, 2013; Khandkar, 2009). Based on their similarities, codes were grouped, collapsed, or expanded into categories (Butler-Kisber, 2010).

Table 1. Example of Unitized Data and Codes

\begin{tabular}{|c|c|}
\hline Examples of unitized data & Examples of codes \\
\hline $\begin{array}{l}\text { "But one thing that I took away from it that was really beautiful . . . } \\
\text { is you can go back there and meet the same people-at this place } \\
\text { where, you know, different conferences over the summers, if you } \\
\text { want" (Participant A). }\end{array}$ & $\begin{array}{l}\text { Emphasis on consistency; } \\
\text { familiarity; comfort; positive } \\
\text { social climate; meaningful } \\
\text { relationships }\end{array}$ \\
\hline $\begin{array}{l}\text { "But I think being with everyone there was helpful, because that- } \\
\text { those are the people that, if we all were on staff together, that } \\
\text { would be the group of people it would be" (Participant B). }\end{array}$ & $\begin{array}{l}\text { Emphasis on group activities; } \\
\text { togetherness; united by a } \\
\text { shared/common goal }\end{array}$ \\
\hline $\begin{array}{l}\text { "I think it helped because you're out, like, in the woods. I don't } \\
\text { know, just kind of in nature and not in, like--taking-you're taking, } \\
\text { like, a break from the real world, I guess, and just kind of helping } \\
\text { you, like, focusing in on what you're learning" (Participant E). }\end{array}$ & $\begin{array}{l}\text { Emphasis on nature; } \\
\text { atypical/distinct experience; } \\
\text { respite; retreat; removal from } \\
\text { distractions/stressors }\end{array}$ \\
\hline
\end{tabular}

Once a category was saturated with at least six coded data excerpts, a rule for inclusion was created (see Table 2). A rule for inclusion is a set of defining criteria proposed as a "statement of fact" (Maykut \& Morehouse, 1994, p. 128). In other words, rules for inclusion outline the conditions of the codes included in each category (Saldaña, 2013). Through this process, 12 categories surfaced, each with its own rule for inclusion.

Upon saturation, the relationships between categories were analyzed for themes. In this context, themes were recurrent, overarching principles that lend meaning to the data and research questions (Braun \& Clarke, 2006). Categories were grouped into sets of three, revealing four emergent themes. 
Journal of Youth Development | http://jyd.pitt.edu/ | Vol. 13 Issue 1-2 DOI 10.5195/jyd.2018.536

Summer Camp Youth Leadership Development

Table 2. Example of Notes for Rules for Inclusion, Categories, and Theme

\begin{tabular}{|l|l|l|}
\hline Notes for rules for inclusion & Categories & Theme \\
\hline $\begin{array}{l}\text { Consistency; familiarity; comfort; positive social } \\
\text { climate; meaningful relationships }\end{array}$ & Building connections & Bridging the gap \\
\hline $\begin{array}{l}\text { Group activities; togetherness; united by a } \\
\text { shared/common goal }\end{array}$ & Sharing experiences & \\
\hline $\begin{array}{l}\text { Nature; atypical/distinct experience; respite; } \\
\text { retreat; removal from distractions/stressors }\end{array}$ & $\begin{array}{l}\text { Separating from the } \\
\text { outside world }\end{array}$ & \\
\hline
\end{tabular}

\section{Part 2: Outcomes}

Next, themes were analyzed for outcomes (see Table 3). Data analysis indicated that each theme yielded an outcome (i.e., a beneficial result, effect, or change stemming from program involvement) (Hatry, van Houten, Plantz, \& Taylor, 1996; Hendricks, Plantz, \& Pritchard, 2008). Outcomes in this study were framed in terms of the knowledge transferred and behavior changed that contributed to participants' experiences and perceptions of the LIT program (MillsScofield, 2012, para. 2).

\section{Part 3: Concepts}

After administering qualitative interviews and analyzing data, a literature review was conducted. Based on a conceptual framework of PYD, youth leadership development, and camp research, the literature review uncovered four related concepts. Each concept consisted of a key element, idea, or topic that was both salient and recurrent in the literature (Fink, 2005; Hart, 1998). These concepts included (a) social relationships; (b) identity and self-image; (c) agency and engagement; and (d) spirituality, ethicality, and morality. Data analysis linked these four concepts with the four themes and their outcomes, illustrated in Table 3. 
Table 3. Alignment of Categories, Rules for Inclusion, Themes, Outcomes, and Concepts from Interview Data

\begin{tabular}{|c|c|c|c|c|}
\hline Categories & $\begin{array}{l}\text { Rule for inclusion: } \\
\text { The data reflect }\end{array}$ & Themes & Outcomes & Concepts \\
\hline Building connections & $\begin{array}{l}\text { participants' emphasis on the } \\
\text { importance of developing meaningful } \\
\text { relationships }\end{array}$ & \multirow{3}{*}{$\begin{array}{l}\text { Bridging the } \\
\text { gap }\end{array}$} & \multirow{3}{*}{ Community } & \multirow{3}{*}{$\begin{array}{l}\text { Social } \\
\text { relationships }\end{array}$} \\
\hline Sharing experiences & $\begin{array}{l}\text { the bonds created among participants } \\
\text { based on activities done together }\end{array}$ & & & \\
\hline $\begin{array}{l}\text { Separating from the } \\
\text { outside world }\end{array}$ & $\begin{array}{l}\text { the effects of an immersive experience } \\
\text { on participants }\end{array}$ & & & \\
\hline $\begin{array}{l}\text { Providing } \\
\text { psychosocial and } \\
\text { emotional safety }\end{array}$ & $\begin{array}{l}\text { participants' need for a judgment-free } \\
\text { space }\end{array}$ & \multirow{3}{*}{$\begin{array}{l}\text { Giving } \\
\text { permission } \\
\text { to be } \\
\text { human }\end{array}$} & \multirow{3}{*}{ Openness } & \multirow{3}{*}{$\begin{array}{l}\text { Identity and } \\
\text { self-image }\end{array}$} \\
\hline $\begin{array}{l}\text { Starting with a clean } \\
\text { slate }\end{array}$ & $\begin{array}{l}\text { participants' desire to begin anew with } \\
\text { equal footing }\end{array}$ & & & \\
\hline $\begin{array}{l}\text { Validating your true } \\
\text { self }\end{array}$ & $\begin{array}{l}\text { the effects of affirmation on } \\
\text { participants' expressions of self-worth } \\
\text { and authenticity }\end{array}$ & & & \\
\hline Taking initiative & participants' proactive dispositions & \multirow{3}{*}{$\begin{array}{l}\text { Rolling up } \\
\text { your sleeves }\end{array}$} & \multirow{3}{*}{ Empowerment } & \multirow{3}{*}{$\begin{array}{l}\text { Agency and } \\
\text { engagement }\end{array}$} \\
\hline Taking control & $\begin{array}{l}\text { participants' ability to exercise choice } \\
\text { and command }\end{array}$ & & & \\
\hline Rallying the troops & $\begin{array}{l}\text { the impact of morale, energy, and } \\
\text { enthusiasm on participants }\end{array}$ & & & \\
\hline $\begin{array}{l}\text { Working behind the } \\
\text { scenes }\end{array}$ & $\begin{array}{l}\text { the value participants placed on serving } \\
\text { others without seeking credit or } \\
\text { attention }\end{array}$ & \multirow{3}{*}{$\begin{array}{l}\text { Serving the } \\
\text { greater } \\
\text { good }\end{array}$} & \multirow{3}{*}{ Character } & \multirow{3}{*}{$\begin{array}{l}\text { Spirituality, } \\
\text { ethicality, } \\
\text { and morality }\end{array}$} \\
\hline $\begin{array}{l}\text { Considering other } \\
\text { points of view }\end{array}$ & $\begin{array}{l}\text { participants' ability to listen and } \\
\text { acknowledge different perspectives }\end{array}$ & & & \\
\hline $\begin{array}{l}\text { Finding a happy } \\
\text { medium }\end{array}$ & $\begin{array}{l}\text { participants' desire to strike a balance } \\
\text { while avoiding extremes }\end{array}$ & & & \\
\hline
\end{tabular}




\section{Findings}

A synthesis of the four emergent themes, their four outcomes, and the four salient concepts recurrent in relevant literature revealed a camp-based model of youth leadership development.

\section{Themes and Outcomes}

Each of the four emergent themes provided insight into LITs' experiences, specifically their feedback on the merits of the LIT program and their notions of leadership based on their participation in the LIT program (see Table 3).

\section{Quadrant 1: Bridging the Gap}

The first theme, bridging the gap, included three categories: (a) building connections, (b) sharing experiences, and (c) separating from the outside world. Data analysis revealed that when people bridge the gap, a sense of community emerges as a central outcome. Participants remarked:

- It-it feels kind of weird cause, like, once you go there-I was only there for a week, and I felt, like, I was there for, like, a lifetime. .. and then getting to know these people as close friends really (laughs) in a week when you can have a class with somebody and, like, not even know their name for the entire year. (Participant $A$ )

- And -that, for me is more the spiritual element ... the getting to know the other person on that deep level and (pause) you know, having just a short amount of time with them, but still, basically they'll be friends for life-is what makes it (pause) special. (Participant D)

- Being a CIT [Counselor-in-Training] this past summer . . . that was a very challenging week (laughs). And, um, we had a really big problem with kids bullying each otherand I think all of the things that we learned in LIT week about how to handle that without, um, saying anything that didn't need to be said and asserting your authority without being (pause) mean, I think that (pause) uh, really helped me reach out a lot-in that situation. (Participant $B$ ) 
Summer Camp Youth Leadership Development

- Half [of the experience in the LIT program] is the escape (pause) and then, I think the other half-it's people... . Especially if you have (pause) you-you just get to kind of, like, leave for a week and, like, come back. (Participant I)

In sum, participants reported that Waycross Camp's LIT program established a structure that offered reprieve from the outside world through its physical location and nurtured a social sphere in which interpersonal connections fostered community. This theme and outcome linked to the concept, social relationships.

\section{Quadrant 2: Giving Permission to be Human}

The second theme, giving permission to be human, included three categories, (a) providing psychosocial and emotional safety, (b) starting with a clean slate, and (c) validating your true self. Data analysis revealed when people give themselves and others permission to be human, a sense of openness emerges as a central outcome. Participants stated:

- Whenever I go to Waycross, I always come back home (pause) feeling a lot better about myself-like, selfesteem-wise . . . cause at camp, there's no, like (pause) there's not really much of a social (pause) kind of hierarchy, like, there is at high school. (Participant J)

- And, you know, going to this place and meeting people like this and really getting to know them and like them-just sharing these things with you and, you know, you having an equal kind of, like, neutral conversation about anything basically and getting them to bring out who you really are-it's really inspiring. (Participant A)

- [In LIT] I've probably, like, taken up some leadership by, um, just really opening up, cause I'm usually kind of shy. (Participant C)

- Waycross is such (pause) kind of a safe haven for people ... Um, and a lot of kids, you know, being away from ... school peers and your parents allows you to (pause) be almost a different person . . . you're not afraid of being judged. Because there's - that's what I love about us is ... . that understanding that whatever you do, whatever you say, you're not going to be judged for it. (Participant D) 


\section{Summer Camp Youth Leadership Development}

Accordingly, participants reported that Waycross Camp's LIT program facilitated a positive environment that affirmed participants' self-worth by creating an equitable, authentic, judgment-free space conducive to emotional openness. This theme and outcome linked to the concept, identity and self-image.

\section{Quadrant 3: Rolling up Your Sleeves}

The third theme, rolling up your sleeves, included three categories, (a) taking initiative, (b) taking control, and (c) rallying the troops. Data analysis revealed when people roll up their sleeves, a sense of empowerment emerges as a central outcome. Participants reflected:

- But also having the ability to (pause) step up and say what needs to be said and do what needs to be done-if the situation calls for it. (Participant $G$ )

- So, like (pause) everyone [in the LIT program] was participating; everyone was, like, doing all the effort they could-to try to make it fun, because everyone wanted it to be fun. And, I feel, like, if it had been with, like, a group of classmates that (pause) they wouldn't have put in the same amount of effort to try to make it enjoyable. (Participant F)

- Like-I said earlier, like, being enthusiastic about learning new things - I think is, um, really important for being able to, like, engage with others. (Participant $H$ )

- And, um, basically I can handle-like, when something unexpected happens, I can handle it way better than I thought I would be able to, like, before it's, you know, something major happened and it was, like, really out of the blue, I would be super shocked and just stunned and just stand there. But now [after the LIT program], I'myou know, I can actually do something about it and be, like, "Well, I think I need to do something now." (Participant A)

In this way, participants reported that Waycross Camp's LIT program encouraged experiential learning by generating opportunities for participants to exhibit initiative, ownership, and enthusiasm, resulting in expressions of empowerment. This theme and outcome linked to the concept, agency and engagement. 


\section{Quadrant 4: Serving the Greater Good}

Finally, the fourth theme, serving the greater good, included three categories, (a) working behind the scenes, (b) considering other points of view, and (c) finding a happy medium. Data analysis revealed when people serve the greater good, a sense of character emerges as a central outcome. Participants disclosed:

- Waycross, I feel, like, teaches you so much about, like, just being a good person (laughs). You know (laughs)? Like, that's definitely been applicable, like, throughout my life. (Participant $H$ )

- I'm not particularly-a particularly extroverted person. And so, I don't know, after LIT, I don't feel, like, you need to be super loud-or out there in order to, like, lead a group of people. And I think people mistake that sometimes . . . I almost feel, like, when you're being a leader, it's good to (pause) not necessarily be the one who comes off and says, "Do this." (Participant G)

- You know, [I] just help out wherever I can. Waycross is a really nice way to help people get up and out and it [LIT] taught me a lot about being (pause) well, (pause) me. (Participant A)

- [In LIT] we especially-you focused a lot of basic kind of (pause) life skills, which are life skills. Um, whether it's, like, conflict resolution or patience or just-kindness, I think was (pause) it's useful no matter what. And sometimes you have to be taught it . . . it's useful and it's something to remember. (Participant I)

Ultimately, participants reported that Waycross Camp's LIT program inspired discernment, empathy, humility, and altruism, all of which challenged participants' personal values, giving rise to an outcome of character. This theme and outcome linked to the concept spirituality, ethicality, and morality. 
Summer Camp Youth Leadership Development

\section{Camp-Based Model of Youth Leadership Development}

A camp-based model of youth leadership development was derived from a synthesis of the four emergent participant themes, their four outcomes, and the four research concepts uncovered during the literature review. This model (see Figure 1) reflects the multidimensional nature of youth leadership development programs; in other words, together, these four quadrants produced outcomes rooted in various facets of personal growth, including affective, cognitive, behavioral, and social dimensions (Garst \& Bruce, 2003).

\section{Figure 1. Camp-Based Model of Youth Leadership Development}

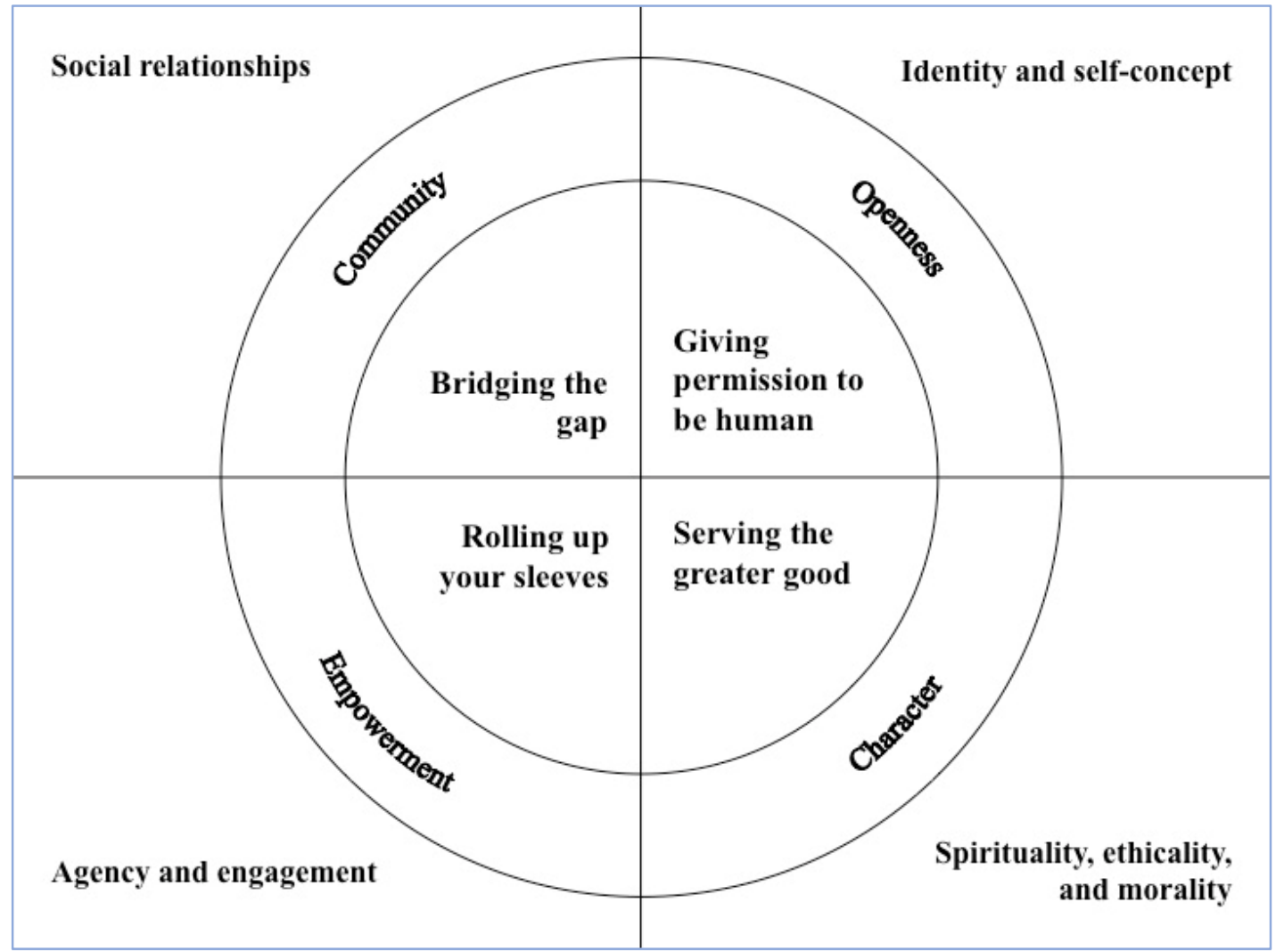

Various theoretical orientations support this model. Self-determination theory posits that choice, not control, fosters the pursuit of long-term goals (Williams, Freedman, \& Deci, 1998). In applying this framework to a camp setting, Hill and Sibthorp (2006) correlated autonomy to heightened self-constructs (e.g., self-management). Another camp study employed the significant life experience framework, which contends that outdoor expedition increases environmental awareness and sustainability efforts. This study found that time spent outdoors promoted awareness of self, spirituality, and surroundings (Daniel, 2007). Finally, Roth and 


\section{Summer Camp Youth Leadership Development}

Brooks-Gunn (2003) and Lerner et al. (2005) cited "five Cs" prominent in PYD literature: competence, connection, confidence, caring, and character, which are strikingly similar to the emergent themes in this study.

Although this camp-based model of youth leadership development aligns with relevant literature, it is distinctive in a number of ways. For one, it is an original contribution to the field that has not been proposed prior to this study. While previous camp leadership models have detailed experiences of young campers (e.g., Bialeschki, Krehbiel, \& Henderson, 2002; Meier \& Henderson, 2011), as well as adolescent and adult camp staff (e.g., Ferrari \& McNeely, 2007; Garst et al., 2012; Garst \& Johnson, 2005), the LIT cohort is unique in its limbo between camper standing and counselor status. Further, this model is notable in part because it is a direct reflection of participants' feedback on the LIT program's assets.

Collectively, the themes, outcomes, and concepts presented in this study echo LIT program participants' overlapping values of camp and perceptions of leadership. This connection is noteworthy in light of studies that indicate inconsistencies between implemented youth leadership education initiatives and the actual needs, interests, and goals of youth participants (Henderson et al., 2007a; Klau, 2006). In contrast, this study provided campers, one of camp's greatest stakeholders (Bialeschki et al., 2007), with a vehicle to voice their needs, interests, and goals. Finally, this model lends itself to outlining effective tenets of a youth leadership development program, and can be utilized as a roadmap for future youth development camp curricula and program visions.

\section{Discussion}

\section{Research Concepts}

The literature review was based on a conceptual framework that included three lenses pertaining to the content of this study: (a) youth development, which explored the structural components and paradigm shifts that contribute to developmental outcomes in youth; (b) youth leadership, which explored leadership theories and practices as a youth initiative; and (c) summer camp, which explored the institution in terms of its programming, setting, objectives, and outcomes. 


\section{Summer Camp Youth Leadership Development}

\section{Quadrant 1: Social Relationships}

The first theme, bridging the gap, and its outcome, community, fall under the umbrella of interpersonal interactions, a concept referred to as social relationships. Camps strive to maintain environments in which healthy relationships can flourish. With its group living arrangements and collective community, social relationships often develop organically at camp (Eccles et al., 2003; Roth \& Brooks-Gunn, 2003). Researchers frequently cite improved interpersonal skills as a direct outcome of the summer camp experience (Bialeschki et al., 2007; Henderson et al., 2007c; Sweatman \& Heintzman, 2004; Thurber et al., 2007). One study found statistically significant increases in campers' social skills, specifically constructs related to peer relationships, after the conclusion of camp (Henderson et al., 2007c). This inclusive environment is well-equipped to foster a social relatedness that deepens participants' sense of community.

\section{Quadrant 2: Identity and Self-Image}

The second theme, giving permission to be human, and its outcome, openness, focus on the individual and sense of self, a concept referred to as identity and self-image. Identity and selfimage relate to facets of an individual, particularly how he/she views and regulates him/herself in a given context or as a part of a larger narrative (Berzonsky, 2004; Bialeschki et al., 2007; Ramsing \& Sibthorp, 2008), including his/her formation of acceptance, competence, validation, and equity (Rinn, 2006). Camps, particularly residential camps, strive to create a safe, welcoming environment that neutralizes socio-economic and cultural barriers (Cargo, Grams, Ottoson, Ward, \& Green, 2003; Garst \& Johnson, 2005). In a meta-analysis of 22 camp studies, elevated self-concept, including self-esteem, was linked to positive camp experiences (Marsh, 1999). Accordingly, camp may serve as a safe setting for enriching self-image through vulnerability, acceptance, and openness.

\section{Quadrant 3: Agency and Engagement}

The third theme, rolling up your sleeves, and its outcome, empowerment, concentrate on participation and active involvement, a concept referred to as agency and engagement. Research suggests that providing opportunities for decision-making nurtures autonomy (Ramsing \& Sibthorp, 2008); whereas confronting challenges generates confidence and taking responsibility cultivates initiative (Cargo et al., 2003; Henderson et al., 2007c). Together, these constructs set the stage for empowerment. By offering a variety of activities for campers to participate in, camp validates campers' decisions, motivating them to stay active and engaged 


\section{Summer Camp Youth Leadership Development}

(Garst et al., 2011). Research supports this notion through significant gains in campers' ability to take initiative and make decisions after the conclusion of camp (Henderson et al., 2007c). Due to its highly participatory nature, camp is a dynamic forum for youth development.

\section{Quadrant 4: Spirituality, Ethicality, and Morality}

The fourth theme, serving the greater good, and its outcome, character, encompass participants' values and motives, a concept referred to as spirituality, ethicality, and morality. Pursuing goals that transcend self-interest is salient to youths' evolving ethical identity (Dawes \& Larson, 2011). During adolescence, youth begin to frame their beliefs, principles, and value systems in alignment with purpose, reflection, and consideration of others (Damon, Menon, \& Cotton Bronk, 2003; Eccles et al., 2003). Heintzman (2009) posited that nature-based recreation (e.g., camp) nurtures spiritual well-being, which is comprised in part of integrity, service, and altruism. Multiple raters in various studies have recorded significant growth in campers' positive values and spirituality from pre- to post-camp (Henderson et al., 2007c; Thurber et al., 2007). Among other maxims, purpose, empathy, and stewardship appear to play a pivotal role in character building at camp.

\section{Limitations}

The limited scope of this research impacted the study in several ways. Difficulty isolating factors, such as family dynamics, as well as socioeconomic status and its byproducts (e.g., level of parental support, number of extracurricular opportunities afforded) posed various challenges (Larson, 2000). Most LITs had prior Waycross Camp experiences, which may have made it difficult for participants to distinguish between the LIT program and past camp sessions. Additionally, youth with an interest in leadership may have been more inclined to enroll in a leadership development program, which may have biased the participant pool (Eccles et al., 2003; Hsuing, 2010).

Select demographic data (e.g., age, gender) were excluded from participants' interviews and subsequent analysis to ensure confidentiality. Taking this omission into account, it is possible that other factors influenced research findings. Further, it is safe to assume that some degree of researcher bias and reactivity effect were at play throughout data collection and analysis (Maxwell, 2013). Therefore, results should be interpreted within the context of the constraints of this study, which limits generalization of these research findings (Cargo et al., 2003; Dawes \& Larson, 2011). 


\section{Trustworthiness}

Credibility is a critical element of trustworthiness, which is bolstered with transparency and persuasiveness. In this study, credibility was established through adherence to grounded theory; systematic, methodical, and consistent use of constant comparison inquiry; and rigor exercised throughout data collection (e.g., attention to detail, including notation of conversational cues, such as pauses, sighs, and laughter). Processes, such as consent forms and interview protocol, maximized participation and streamlined data collection.

It is important to note that these findings summarize the dominant themes, outcomes, and concepts uncovered in this study. While minor, discrepancies in participants' feedback did exist. For example, some participants reported that the LIT program staff positively impacted their experiences, while others stated that the LIT program staff had either a neutral or minimal influence. Additionally, some participants expressed dissatisfaction with the amount of time the LIT program spent indoors in a classroom format, while others stated they were satisfied with this arrangement. In sum, while these responses did not alter research findings, they do contribute to the study's trustworthiness by demonstrating variations in participant feedback (Shenton, 2004).

Likewise, credibility was strengthened through reflexivity, specifically through reflexive memos. Recorded after each interview, reflexive memos afforded the opportunity for reevaluation, reassessment, and reflection. Acknowledging inherent biases, assumptions, and preconceptions integrated accountability and openness into research practice (Butler-Kisber, 2010; Day, 2012). While personal values and experiences undoubtedly influenced this study, the nature of qualitative research is not to establish objective truths, but rather to comprehend how context affects participants' meaning-making. One such context is relational, contingent on participants' interactions with the researcher, making joint knowledge construction inevitable (Hsuing, 2010).

\section{Implications}

As Ramsing and Sibthorp (2008) reported, programs aiming to maximize youth leadership outcomes may be best served to consider how youth experience leadership in accordance with their perceptions and values of leadership. Put another way, it is important to examine youth's perspectives on PYD programs' strengths in order to understand how they experience leadership growth in camp contexts, and to reflect these findings in programs' design and 
Summer Camp Youth Leadership Development

implementation to maximize their effectiveness and long-term impact. In short, youth perspectives matter and their input has an impact on the success of PYD programs.

While additional research is needed to strengthen these findings, basic principles can be gleaned from this research and subsequently, implemented into camp-based leadership programming. First and foremost, as a general rule of best practice, participant feedback should be taken into consideration and addressed in future iterations of programming. Specific to this study, the camp-based model of youth leadership development is comprised of research concepts uncovered during the literature review, as well as themes and outcomes that emerged from qualitative interviews conducted with LIT program participants 18 months after the program's completion.

Figure 2: Camp Activities Mapped to the Camp-Based Model of Youth Leadership Development

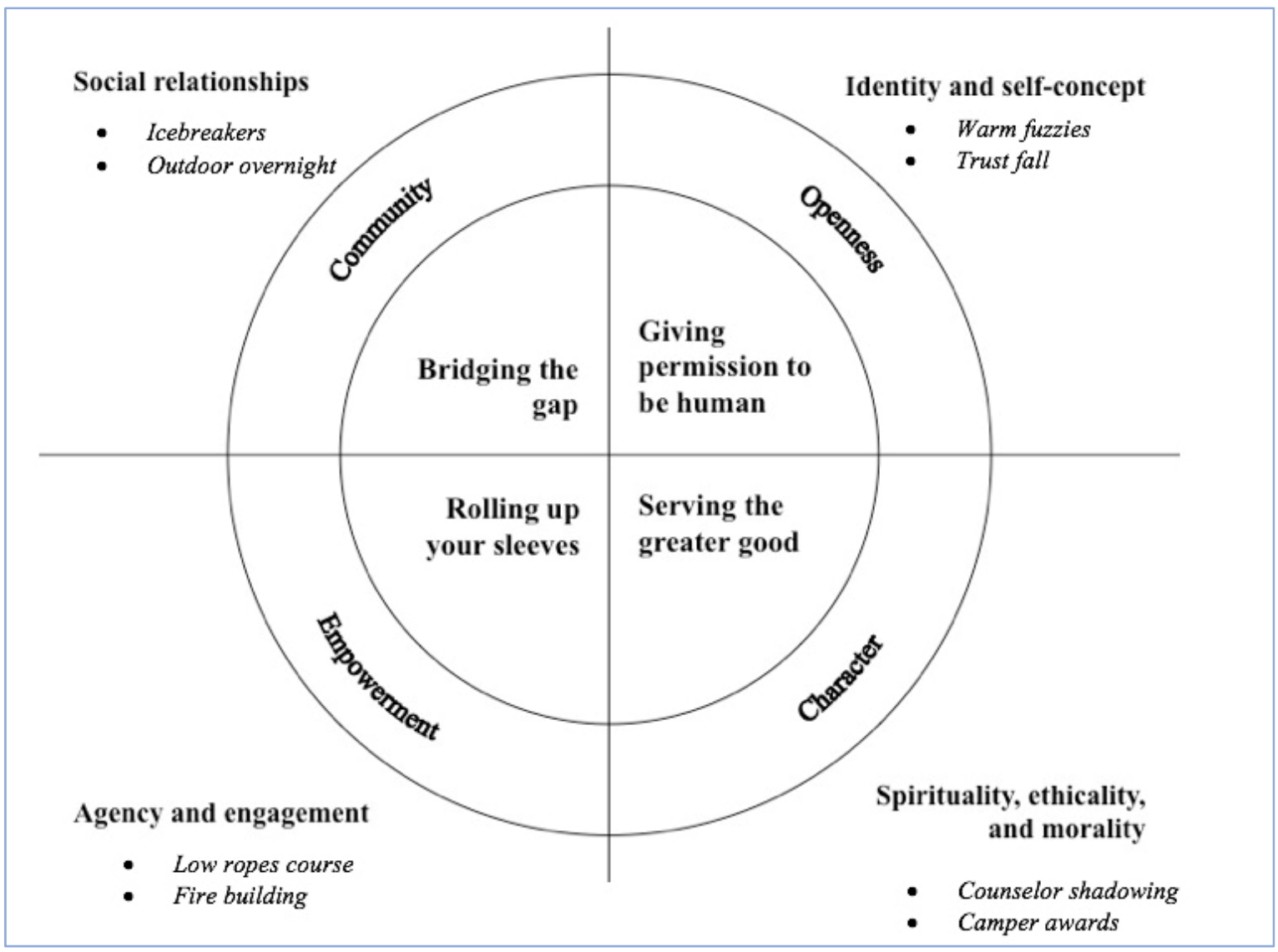




\section{Summer Camp Youth Leadership Development}

Based on this model, camp practitioners may choose to design a camp-based youth leadership development program by mapping PYD activities to these quadrants (see Figure 2). Using the Waycross Camp LIT program as an example, program participants partake in a variety of group activities, such as:

- Ice breakers: LITs engage in introductory games designed to encourage dialogue, levity, and camaraderie.

- Outdoor overnight: LITs hike to a wooded location, prepare meals over an open fire, and sleep on tarps under the stars.

- Warm fuzzies: LITs write personalized, individualized affirmations to one another.

- Trust fall: LITs intentionally fall and rely on other participants to catch them.

- Low ropes course: LITs attempt a series of challenging, team-building exercises involving low elements.

- Fire building: LITs work in pairs to learn how to start a fire using kindling and matches or flint and steel.

- Counselor shadowing: LITs shadow camp counselors, learn about their roles with campers, and assist them with their daily responsibilities.

- Camper awards: LITs create and present personalized awards to individual campers during a ceremony.

In reviewing the rules for inclusion outlined in Table 3, a camp practitioner can map each activity to one quadrant (i.e., one of the four corresponding themes, outcomes, and concepts). For example, ice breakers address the rules for inclusion outlined in Quadrant 1. These include participants' emphasis on the importance of developing meaningful relationships, the bonds created among participants based on activities done together, and the effects of an immersive experience on participants. Therefore, ice breakers would be mapped to Quadrant 1.

To date, the camp-based model of youth leadership development has not been studied as an evaluative tool. However, by mapping activities to the quadrants outlined in this model, camp practitioners create a visual representation of the primary themes, outcomes, and concepts their activities are designed to address. Used in concert with pre- and post-program evaluations, this model provides another approach to articulating, refining, and achieving positive outcomes. 


\section{Conclusion}

This research provides insight into adolescents' perceptions of a camp-based youth leadership development program's best practices. In some capacity, rigorous constant comparison inquiry and grounded theory answer the cry for additional camp outcomes research (Henderson et al., 2007b). Data from qualitative interviews demonstrated a complex, multidimensional understanding of the LIT program's merits, yielding a camp-based model of youth leadership development. This model is notable for its congruence with current, relevant theoretical orientations; the demographic it gives voice to (i.e., adolescent campers); and the future programs it may guide. Lastly, this study illustrates adolescents' understanding of leadership in tandem with contemporary, relational approaches to leadership and PYD.

This study supplements current camp literature by affirming that youth leadership development programs can be implemented effectively in residential summer camp settings. Indeed, findings suggest that camp may be a largely overlooked resource in the PYD and youth leadership realms. Findings assert adolescence as a period of reflection, personal growth, and maturation (Roberts, Caspi, \& Moffitt, 2001), and that youth involved in PYD, leadership-focused programs tend to be receptive to relevant activities that support community, openness, empowerment, and character (Dawes \& Larson, 2011). Although predictive relationships between themes, outcomes, and concepts need to be examined more closely and the aggregate benefits of the camp experience are not fully understood (Bialeschki et al., 2007; Dawes \& Larson, 2011), it is evident that all LIT program participants interviewed for this study found value in the camp experience and in the leadership development initiatives implemented therein.

\section{References}

Berzonsky, M. D. (2004). Identity processing style, self-construction, and personal epistemic assumptions: A social-cognitive perspective. European Journal of Developmental Psychology, 1(4), 303-315.

Bialeschki, M. D., Henderson, K. A., \& James, P. A. (2007). Camp experiences and developmental outcomes for youth. Child and Adolescent Psychiatric Clinics of North America, 16, 769-788.

Bialeschki, M. D., Krehbiel, A., \& Henderson, K. (2002). Outcomes of camping: Perceptions from camper focus groups. Research in Outdoor Education, 6, 147-156.

Braun, V., \& Clarke, V. (2006). Using thematic analysis in psychology. Qualitative Research in Psychology, $3(2), 77-101$. 
Journal of Youth Development | http://jyd.pitt.edu/ | Vol. 13 Issue 1-2 DOI 10.5195/jyd.2018.536

\section{Summer Camp Youth Leadership Development}

Butler-Kisber, L. (2010). Qualitative inquiry: Thematic, narrative, and arts-informed perspectives. London, UK: Sage.

Cargo, M., Grams, G. D., Ottoson, J. M., Ward, P., \& Green, L. W. (2003). Empowerment as fostering positive youth development and citizenship. American Journal Health Behavior, 271), S66-S79.

Catalano, R. F., Berglund, M. L, Ryan, J. A. M., Lonczak, H. S., \& Hawkins, J. D. (2004). Positive youth development in the United States: Research findings on evaluations of positive youth development programs. Annals of the American Academy of Political and Social Science, 591, 98124.

Crooks, D. L. (2001). The importance of symbolic interaction in grounded theory research on women's health. Health Care for Women International, 22, 11-27.

Damon, W., Menon, J., \& Cotton Bronk, K. (2003). The development of purpose during adolescence. Applied Developmental Science, $7(3), 119-128$.

Daniel, B. (2007). The life significance of a spiritually oriented, Outward Bound-type wilderness expedition. The Journal of Experiential Education, 29(3), 386-389.

Dawes, N. P., \& Larson, R. (2011). How youth get engaged: Grounded-theory research on motivational development in organized youth programs. Developmental Psychology, 4X1), 259-269.

Day, S. (2012). A reflexive lens: Exploring dilemmas of qualitative methodology through the concept of reflexivity. Qualitative Sociology Review, 8(1), 61-85.

Eccles, J. S., Barber, B. L., Stone, M., \& Hunt, J. (2003). Extracurricular activities and adolescent development. Journal of Social Issues, 59(4), 865-889.

Ferrari, T. M., \& McNeely, N. N. (2007). Positive youth development: What's camp counseling got to do with it? Findings from a study of Ohio 4-H camp counselors. Journal of Extension, 45(2).

Fink, A. (2005). Conducting research literature reviews: From the internet to paper. Thousand Oaks, CA: Sage.

Garst, B. A., Browne, L. P., \& Bialeschki, M. D. (2011). Youth development and the camp experience. New Directions for Youth Development, 130, 73-87.

Garst, B. A., \& Bruce, F. A. (2003). Identifying 4-H camping outcomes using a standardized evaluation process across multiple 4-H educational centers. Journal of Extension, 41(3).

Garst, B. A., Franz, N. K., Peters, B., Smith, C., \& Baughman, S. (2012). Using single-case participatory action research as a methodology to explore Appalachian summer camp communities. PRISM: $A$ Journal of Regional Engagement, 1(1), 19-31.

Garst, B. A., \& Johnson, J. (2005). Adolescent leadership skill development through residential 4-H camp counseling. Journal of Extension, 43(5).

Garton, M. S., Miltenberger, M., \& Pruett, B. (2007). Does 4-H camp influence life skill and leadership development? Journal of Extension, 45(4). 
Journal of Youth Development | http://jyd.pitt.edu/ | Vol. 13 Issue 1-2 DOI 10.5195/jyd.2018.536

Summer Camp Youth Leadership Development

Glaser, B. G., \& Strauss, A. L. (2009). The discovery of grounded theory: Strategies for qualitative research. New Brunswick, Canada: Transaction.

Gläser, J., \& Laudel, G. (2013). Life with and without coding: Two methods for early-stage data analysis in qualitative research aiming at causal explanations. Forum Qualitative Sozialforschung/Forum: Qualitative Social Research, 14(2).

Hastings, L. J., Barrett, L. A., Barbuto, J. E., \& Bell, L. C. (2011). Developing a paradigm model of youth leadership development and community engagement: A grounded theory. Journal of Agricultural Education, 52(1), 19-29.

Hart, C. (1998). Doing a literature review: Releasing the social science research imagination. Thousand Oaks, CA: Sage.

Hatry, H., van Houten, T., Plantz, M. C., \& Taylor, M. (1996). Measuring program outcomes: A practical approach. Alexandria, VA: United Way of America.

Heintzman, P. (2009). Nature-based recreation and spirituality: A complex relationship. Leisure Sciences, 32(1), 72-89.

Henderson, K. A., Bialeschki, M. D., \& James, P. A. (2007a). Overview of camp research. Child Adolescent Psychiatric Clinics of North America, 16, 755-767.

Henderson, K. A., Bialeschki, M. D., Scanlin, M. M., Thurber, C., Whitaker, L. S., \& Marsh, P. E. (2007b). Components of camp experiences for positive youth development. Journal of Youth Development, $1(3), 1-12$.

Henderson, K. A., Whitaker, L. S., Bialeschki, M. D., Scanlin, M. M., \& Thurber, C. (2007c). Summer camp experiences: Parental perceptions of youth development outcomes. Journal of Family Issues, 28(8), 987-1007.

Hendricks, M., Plantz, M. C., \& Pritchard, K. J. (2008). Measuring outcomes of United Way-funded programs: Expectations and reality. New Directions for Evaluation, 119, 13-35.

Hill, E., \& Sibthorp, J. (2006). Autonomy support at diabetes camp: A self determination theory approach to therapeutic recreation. Therapeutic Recreation Journal, 4O(2), 107-125.

Hsuing, P. C. (2010). Reflexivity: A process of reflection. Retrieved from http://www.utsc.utoronto.ca/ pchsiung/LAL/reflexivity

Khandkar, S. H. (2009). Open coding. Retrieved from http://pages.cpsc.ucalgary.ca/ saul/wiki/uploads/CPSC681/opencoding.pdf

Klau, M. (2006). Exploring youth leadership in theory and practice. New Directions for Youth Development, 109, 57-87.

Larson, R. (2000). Toward a psychology of positive youth development. American Psychologist, 55, 170183.

Lerner, R. M., Almerigi, J. B., Theokas, C., \& Lerner, J. V. (2005). Positive youth development: A view of the issues. Journal of Early Adolescence, 25(1), 10-16. 
Journal of Youth Development | http://jyd.pitt.edu/ | Vol. 13 Issue 1-2 DOI 10.5195/jyd.2018.536 Summer Camp Youth Leadership Development

Marsh, P. E. (1999). What does camp do for kids? A meta-analysis of the influence of organized camping experience on the self constructs of youth. Unpublished Master of Science thesis, Department of Recreation and Park Administration, Indiana University, IN.

Maxwell, J. A. (2013). Qualitative research design: An interactive approach. London, UK: Sage.

Maykut, P. S., \& Morehouse, R. (1994). Beginning qualitative research: A philosophic and practical guide. London, UK: Falmer Press.

Meier, J. F., \& Henderson, K. A. (2011). Camp counseling: Leadership and programming for the organized camp. Long Grove, IL: Waveland Press.

Mills-Scofield, D. (2012, November 26). It's not just semantics: Managing outcomes vs, outputs. Retrieved from https://hbr.org/2012/11/its-not-just-semantics-managing-outcomes

Ramsing, R., \& Sibthorp, J. (2008). The role of autonomy support in summer camp programs: Preparing youth for productive behaviors. Journal of Park and Recreation Administration, 26(2), 61-77.

Rinn, A. N. (2006). Effects of a summer program on the social self-concepts of gifted adolescents. Prufrock Journal, 172), 65-75.

Roberts, B. W., Caspi, A., \& Moffitt, T. E. (2001). The kids are alright: Growth and stability in personality development from adolescence to adulthood. Journal of Personality and Social Psychology, 81(4), 670-683.

Roth, J. L., \& Brooks-Gunn, J. (2003). What exactly is a youth development program? Answers from research and practice. Applied Developmental Science, 72), 94-111.

Saldaña, J. (2013). The coding manual for qualitative researchers. Los Angeles, CA: Sage.

Shenton, A. K. (2004). Strategies for ensuring trustworthiness in qualitative research projects. Education for Information, 22, 63-75.

Sweatman, M. M., \& Heintzman, P. (2004). The perceived impact of outdoor residential camp experience on the spirituality of youth. World Leisure Journal, 46(1), 23-31.

Thomas, H. (1996). Youth leadership: Teaching essential proficiencies at camp. The Camping Magazine, 68(4), 25-27.

Thurber, C. A., Scanlin, M. M., Scheuler, L., \& Henderson, K. A. (2007). Youth development outcomes of the camp experience: Evidence for multidimensional growth. Journal of Youth Adolescence, 36, 241-254.

Waycross Camp and Conference Center. (2014). Session information. Retrieved from http://waycrosscenter.org/session-information/

Williams, G. C., Freedman, Z. R., \& Deci, E. L. (1998). Supporting autonomy to motivate patients with diabetes for glucose control. Diabetes Care, 10, 1644-1651. 